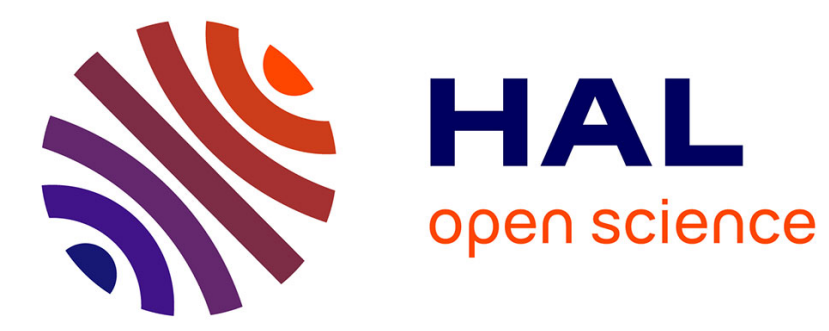

\title{
The Impact of New Instruments on Surgical Performance in Natural Orifice Translumenal Endoscopic Surgery
}

Amine Chellali, Caroline G. L. Cao

\section{- To cite this version:}

Amine Chellali, Caroline G. L. Cao. The Impact of New Instruments on Surgical Performance in Natural Orifice Translumenal Endoscopic Surgery. HFES 2013, Sep 2013, San Diego, CA, United States. pp.663-667, 10.1177/1541931213571143 . hal-00903781

HAL Id: hal-00903781

https://hal.science/hal-00903781

Submitted on 13 Nov 2013

HAL is a multi-disciplinary open access archive for the deposit and dissemination of scientific research documents, whether they are published or not. The documents may come from teaching and research institutions in France or abroad, or from public or private research centers.
L'archive ouverte pluridisciplinaire HAL, est destinée au dépôt et à la diffusion de documents scientifiques de niveau recherche, publiés ou non, émanant des établissements d'enseignement et de recherche français ou étrangers, des laboratoires publics ou privés. 


\title{
The Impact of New Instruments on Surgical Performance in Natural Orifice Translumenal Endoscopic Surgery
}

\author{
Amine Chellali ${ }^{1}$, Caroline G.L. Cao ${ }^{2}$ \\ ${ }^{1}$ Department of Surgery, Cambridge Health Alliance - Harvard Medical School, Cambridge, MA \\ ${ }^{2}$ Department of Biomedical, Industrial and Human Factors Engineering, Wright State University, Dayton, \\ $\mathrm{OH}$
}

\begin{abstract}
Natural Orifice Translumenal Endoscopic Surgery (NOTES) is a recent emerging technique for performing general surgery procedures such as cholecystectomy (gallbladder removal). However, the advantages of NOTES over conventional laparoscopic surgery, the current gold standard, are still questionable. The aim of this study was to show the impact of introducing new surgical instruments in the NOTES technique on surgical performance in a cholecystectomy as compared to conventional laparoscopic surgery. A set of videos from real cholecystectomy cases performed using these two different techniques were analyzed. Hierarchical task decomposition and timeline analysis were conducted for each technique. A comparison to show variations between the two techniques at the task level is presented to highlight the technical issues, and their effects on performance, associated with the use of current endoscopic tools in the NOTES technique. The results show a longer procedural time in the NOTES technique than in the laparoscopic technique with the highest increase in surgical time for dissection tasks. The tools used for dissection were also shown to be inadequate for the task based on the motion analysis. Using this systematic method of analysis, new surgical techniques can be assessed based on performance measures, while areas of design improvement in surgical tools can be identified and related to the performance assessment.
\end{abstract}

\section{INTRODUCTION}

Natural orifice translumenal endoscopic surgery (NOTES) is a new minimally invasive surgical technique that combines aspects of laparoscopic surgery with flexible endoscopic surgery, with the aim of obtaining a scare free surgery. In fact, having no surgical scars is desirable from the patients' perspective. Moreover, the technique is expected to offer other benefits to the patients such as less pain, a faster postoperative recovery, a shorter hospitalization time, fewer complications related to the incisions, and a possibly decreased inflammatory response during surgery (CuadradoGarcia, et al., 2011; Zornig, et al., 2008; Zorron, et al., 2008). However, it is more challenging for the surgeons than existing techniques (Asakuma, et al., 2009), introducing both technical and human factors issues, including task performance and effective use of surgical equipment.

Though adopted as the gold standard, current laparoscopic surgery techniques present several challenges to surgeons that differ from those seen with traditional open surgery techniques (Tessier, Zhang, \& Cao, 2012). Previous research has shown that laparoscopic surgery is associated with various human factors issues, such as difficult hand-eye coordination due to the indirect view of the operative field (Breedveld \& Wentink, 2001); lack of haptic feedback due to the indirect manipulation with laparoscopic instruments (Stassen, Dankelman, \& Grimbergen, 2001); and increased muscular fatigue due to the limited degrees of freedom for manipulating the instruments, which forces the surgeon's arms and wrists to end up in odd, unnatural positions (Berguer, Forkey, \& Smith, 1999).

Similarly, the use of flexible endoscopes has been associated with spatial navigation problems. An analysis of colonoscopy has shown that clinicians can easily be disoriented due to the insufficient degrees of freedom to control the endoscope, the dynamic nature of the colon, the lack of haptic feedback, and the lack of landmarks for spatial orientation (Cao \& Milgram, 2000).

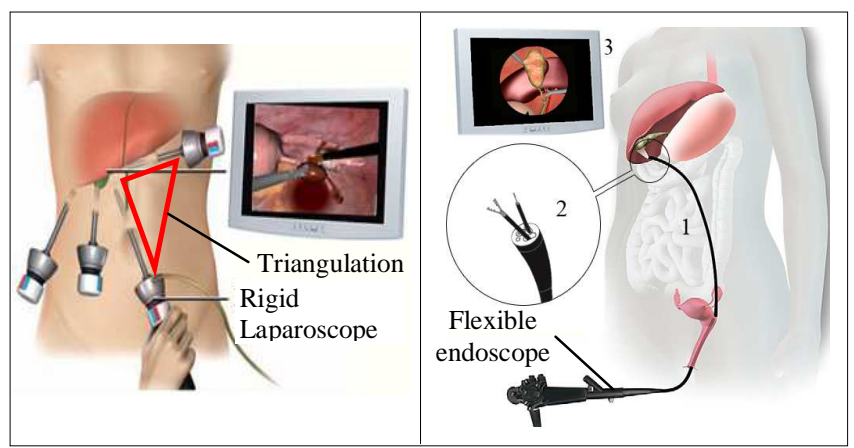

Figure 1: differences in setup between 4-ports laparoscopic cholecystectomy (Left) and trasnvaginal NOTES cholecystectomy (Right) and issues associated with the NOTES technique: (1) lack of platform stability due to the use of flexible endoscopes in the large abdominal cavity (a rigid laparoscope is used in laparoscopic surgery); (2) lack of triangulation due to endoscopic instruments arriving in parallel (instuments in laparoscpic surgery are installed in a triangular fashion to facilitate munipulation); (3) poor visibility due to limited video resolution and navigation using the flexible endoscope (laparoscopes have a better resolution and are easier to manipulate).

In addition to the previous indentified issues, NOTES brings out new issues specific to this technique. The use of flexible endoscopes in the large abdominal cavity and of endoscopic instruments arriving in parallel and in-line with the light source (Figure 1), are associated with difficulties such as poor visibility, a lack of tool triangulation (in laparoscopic surgery, instruments are setup in a triangular fashion to allow better manipulation of tools and better access to the surgical site), and an instability of the operating platform (Kondo, et al., 2011). A previous evaluation of the NOTES technique revealed an increased complexity of surgical tasks and 
inappropriateness of the tools in NOTES compared to laparoscopic surgery (Tessier, Zhang, \& Cao, 2012).

Transvaginal cholecystectomy (gallbladder removal) is the most commonly performed NOTES procedure on humans to date (Auyang, Santos, Enter, Hungness, \& Soper, 2011). Subsequently, the study presented here is specific to cholecystectomy performed either laparoscopically or transvaginally using the NOTES technique. In laparoscopic surgery, a typical procedure (Figure 1) consists of the following steps (Jones, Maithel, \& Schneider, 2006). First, the gallbladder is located visually using the laparoscope and retracted using graspers. The tissue surrounding the cystic duct and artery is dissected using a laparoscopic dissector in order to obtain a critical view of safety (CVS). Once the cystic artery and duct are isolated, they are clipped using a clip applier and divided between clips using laparoscopic scissors. The gallbladder is then dissected from the liver bed using a laparoscopic electrosurgical dissection tool and removed with a retrieval bag.

\section{Objectives}

Previous research indicates that the existing equipment used in NOTES cholecystectomy is inappropriate, leading to difficulties when performing the surgeries as compared with the conventional laparoscopic technique. However, no systematic evaluation showing the effects of the technical issues on the surgical performance has been done. The objective of this study was to assess the effects of the technology currently used in the NOTES technique on the performance in different surgical tasks compared to the current gold standard - laparoscopic surgery.

\section{METHODS}

Hierarchical task decomposition is a valuable research methodology from Human Factors that has been used in previous studies for analyzing minimally invasive surgery, to understand the complexities of procedures, with an aim to improve training systems (Cao, et al., 1999; MacKenzie, Cao, Ibbotson, \& Lomax, 2001). Based on video analysis, the hierarchical decomposition technique was used in this study to describe and compare NOTES with laparoscopic cholecystectomy. A total of 540 minutes of videos of the endoscopic and laparoscopic views from eight live operations were analyzed (four NOTES cases and four laparoscopic cases). The videos were provided by different expert surgeons, each of whom with at least 5 years of experience in the chosen technique.

The decomposition method is similar to the one used previously in Cao et al., (1999) for laparoscopic

cholecystectomy. It consists of repeated viewing of the video sequences to identify observable events to map onto surgical goals. From observable surgical events on the videos, the beginnings and endings of the surgical steps, sub-steps, and tasks were operationally defined. This allowed a systematic breakdown of the complex surgical procedures into a clear sequence of events and actions that could also be timed. The hierarchical decomposition for laparoscopic cholecystectomy presented in Cao et al. (1999) used a tree diagram to visualize the structure of the surgical procedure. We have updated it (Figure 2) for our use here. Using the task tree to visualize, variations at any level of analysis can be noted and their effects to the overall procedure performance can be examined. Selected tasks are presented here to illustrate the effects of instrument variation on the total operating time of the same surgical procedure.

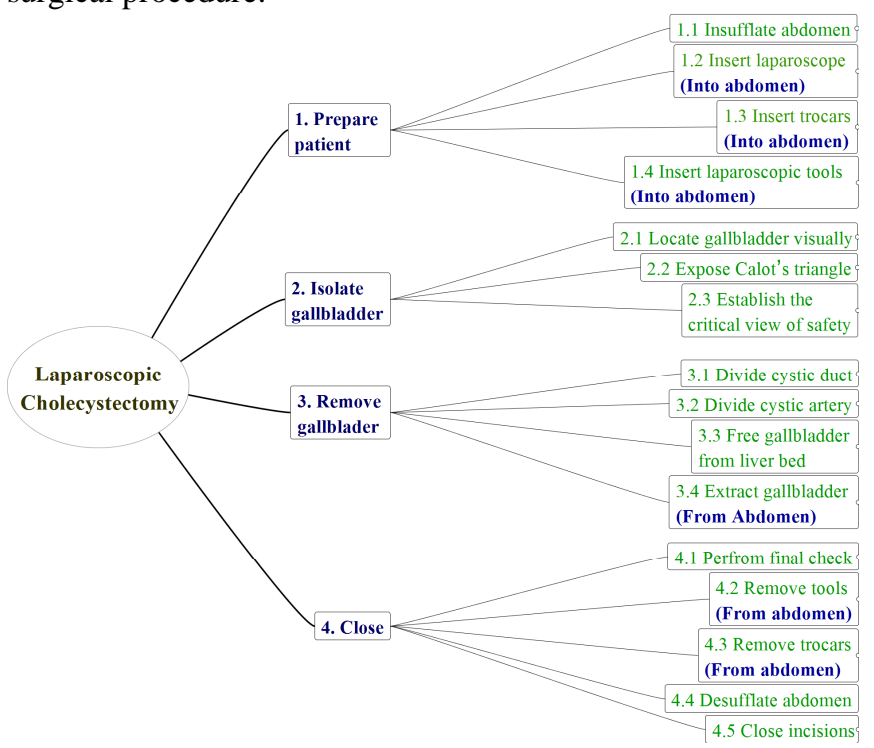

Figure 2: The updated task decomposition tree at the steps and substeps levels for the laparoscopic cholecystectomy (Cao, et al., 1999)

\section{RESULTS}

\section{Hierarchical Decomposition}

The video analysis of the four NOTES cases resulted in a hierarchical decomposition of the transvaginal NOTES cholecystectomy procedure with increasing level of details, from surgical steps, substeps, tasks and subtasks. The logical breakdown of surgical procedures into steps and tasks was then verified independently by five experienced surgeons using the task tree diagrams. Figure 3 shows the generated tree diagram for the transvaginal NOTES technique at the steps and substeps levels.

Comparison of the two task trees (Figure 2 and Figure 3) revealed that while they are similar at the steps level they vary greatly at the substeps level. The major differences observed at this level were:

- The route being used to introduce the instruments: abdomen (for laparoscopic surgery) versus abdomen and vagina (for transvaginal NOTES).

- The type of instruments being used: laparoscopic instruments (for laparoscopic surgery) versus a combination of endoscopic and laparoscopic instruments (for transvaginal NOTES). 


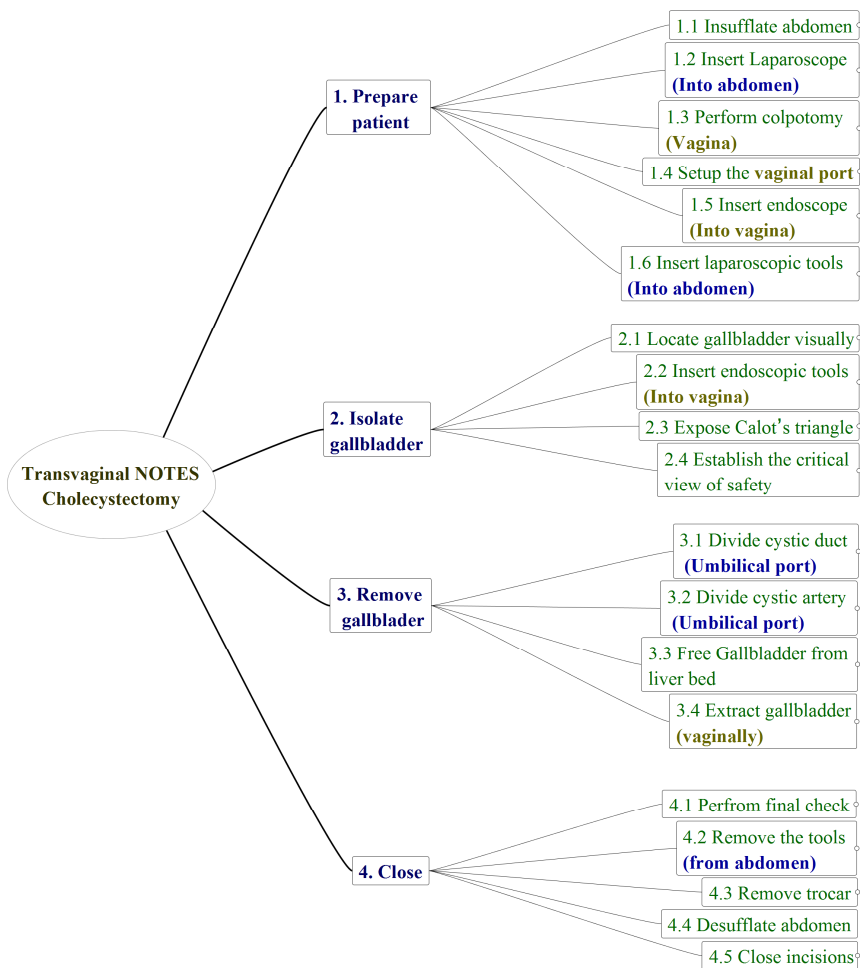

Figure 3: the task decomposition tree at the steps and substeps levels for the transvaginal NOTES cholecystectomy

\section{Timeline Analysis}

All of the collected videos (both laparoscopic and NOTES cases) started when the visualization instrument entered the abdomen, and ended when the gallbladder was removed from the abdomen. Therefore, the timeline analysis was focused only on the surgical tasks visible on the videos-"isolate the gallbladder" and "remove the gallbladder". For that purpose, the beginnings and endings of the related substeps were operationally defined (Table 1).

Table 1: definition of beginnings and endings of substeps

\begin{tabular}{|l|l|l|}
\hline $\begin{array}{l}\text { Observed surgical } \\
\text { substeps }\end{array}$ & Beginning & Ending \\
\hline \multicolumn{3}{|c|}{ 2. Isolate the gallbladder } \\
\hline $\begin{array}{l}\text { 2.1 Locate } \\
\text { gallbladder visually }\end{array}$ & $\begin{array}{l}\text { The first tool contacts } \\
\text { the abdomen }\end{array}$ & Gallbladder is exposed \\
\hline $\begin{array}{l}\text { 2.2 Insert } \\
\text { Endoscopic tools } \\
\text { (only for NOTES) }\end{array}$ & Gallbladder is exposed & $\begin{array}{l}\text { The retraction tool } \\
\text { contacts gallbladder }\end{array}$ \\
\hline $\begin{array}{l}\text { 2.3 (2.2) Expose } \\
\text { Calot's triangle }\end{array}$ & $\begin{array}{l}\text { The retraction tool } \\
\text { contacts gallbladder }\end{array}$ & $\begin{array}{l}\text { The dissection tool } \\
\text { contacts gallbladder }\end{array}$ \\
\hline $\begin{array}{l}\text { 2.4 (2.3) Establish } \\
\text { the CVS }\end{array}$ & $\begin{array}{l}\text { The dissection tool } \\
\text { contacts gallbladder }\end{array}$ & $\begin{array}{l}\text { The clip applier contacts } \\
\text { the duct }\end{array}$ \\
\hline \multicolumn{3}{|l|}{ 3. Remove the gallbladder } \\
\hline $\begin{array}{l}\text { 3.1 Divide cystic } \\
\text { duct }\end{array}$ & $\begin{array}{l}\text { The clip applier } \\
\text { contacts the duct }\end{array}$ & Cystic duct is divided \\
\hline $\begin{array}{l}\text { 3.2 Divide cystic } \\
\text { Artery }\end{array}$ & Cystic duct is divided & Cystic artery is divided \\
\hline $\begin{array}{l}\text { 3.3 Free gallbladder } \\
\text { from liver bed }\end{array}$ & Cystic artery is divided & $\begin{array}{l}\text { Gallbladder is detached } \\
\text { from liver bed }\end{array}$ \\
\hline $\begin{array}{l}\text { 3.4 Extract } \\
\text { gallbladder }\end{array}$ & $\begin{array}{l}\text { Gallbladder is detached } \\
\text { from liver bed }\end{array}$ & $\begin{array}{l}\text { Gallbladder is removed } \\
\text { from abdomen }\end{array}$ \\
\hline
\end{tabular}

The timeline analysis results (Figure 4) show that the time to isolate the gallbladder was much longer in NOTES.
While this increase in time was observed in all the substeps, it was greater in "establish the critical view of safety". Also, the results show that the time to remove the gallbladder was increased in NOTES. The increase in time was greatest in the "free the gallbladder from liver bed" substep. The decomposition of these two substeps revealed a common point between them - both of them included dissection tasks. This suggests more difficulties to perform dissection in the NOTES technique at the task level.

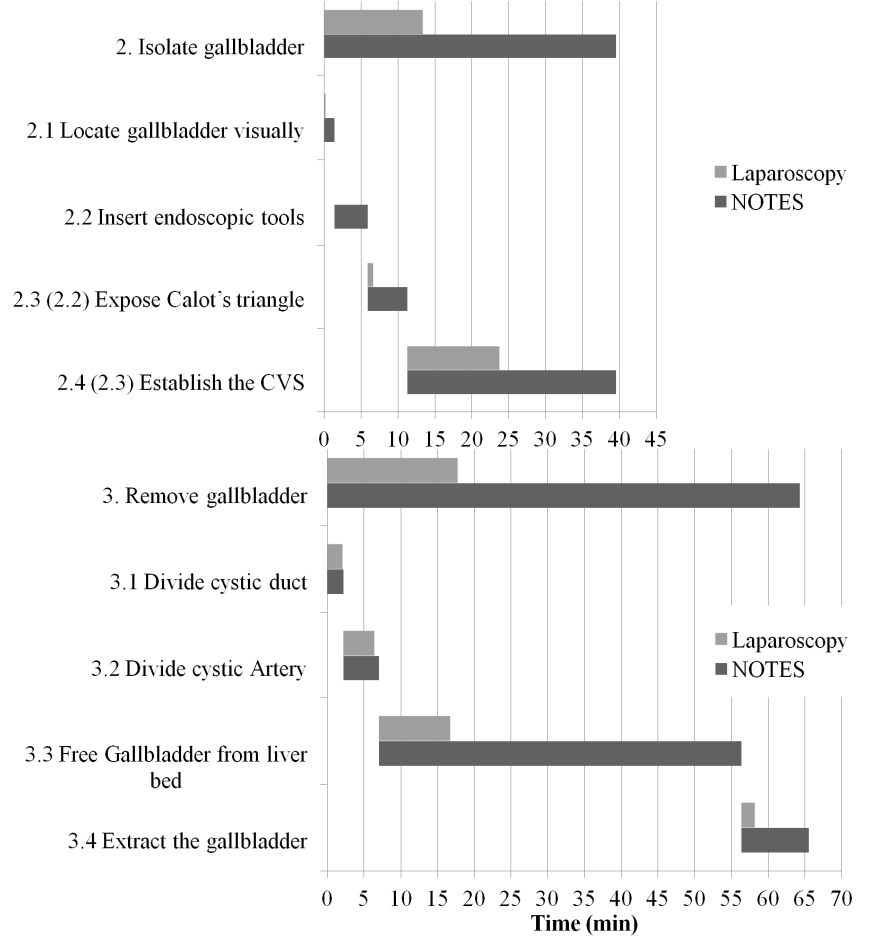

Figure 4: Timeline for steps and related substeps (top: "isolation of the gallbladder"; bottom: "removal of the gallbladder")

\section{Analysis of Dissection Tasks and Subtasks}

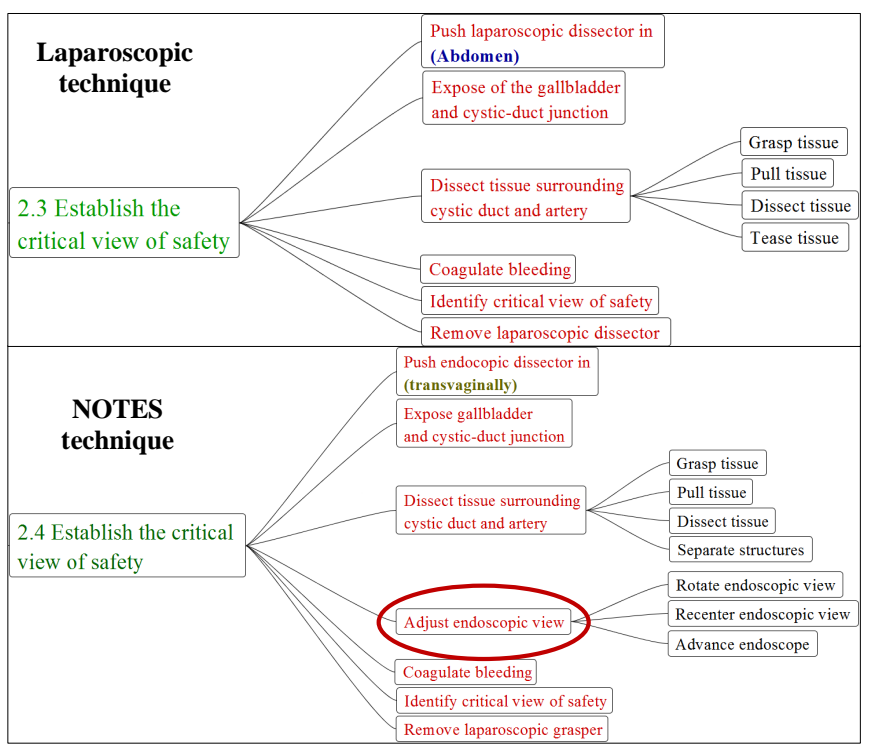

Figure 5: Establishing the critical view of safety substep and related surgical tasks and sub-tasks (Top: using the laparoscopic technique, Bottom: using the transvaginal NOTES technique) 
The analysis of the substeps in question shows that different factors contributed to the increase in time for these substeps. First, the decomposition of this substep revealed the existence of an additional task in NOTES of "adjusting the endoscopic view" that is not found in laparoscopic surgery (Figure 5). The timeline analysis (Figure 6) shows that this additional task contributed to a longer operation time by an average of 6 minutes in the NOTES cases. Second, the average duration of the dissection task was much longer in NOTES than in laparoscopic surgery. Finally, the remaining tasks required slightly more time in laparoscopic surgery than in NOTES, but the total time for these "other tasks" accounts for only $7.8 \%$ of the entire laparoscopic procedure (Figure 6).

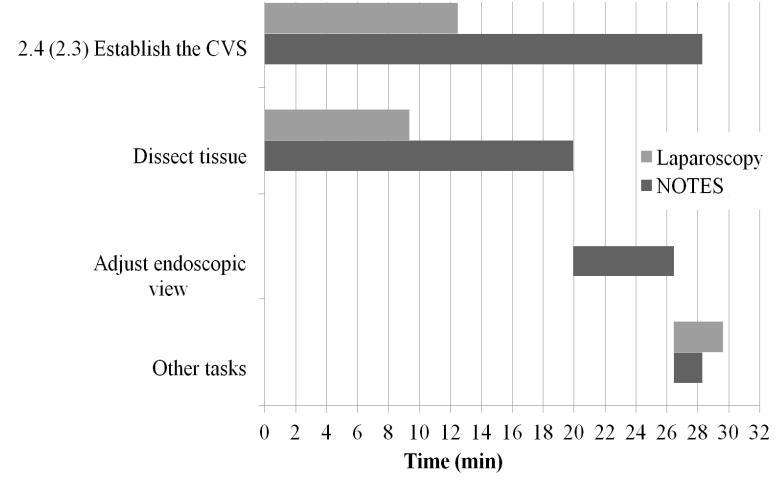

Figure 6: Timeline for "establishing the critical view of safety subtask and realted surgical tasks

\section{DISCUSSION}

One of the most critical instruments for NOTES is the flexible endoscope. The endoscope provides visualization and also serves as a "port" for endoscopic instrumentations. Our timeline analysis at the steps and substeps levels indicates that the use of the flexible endoscope and the endoscopic instruments was associated with a longer procedural time in the NOTES technique than in the laparoscopic technique.

A deeper analysis revealed that the dissection tasks in "establishing the critical view of safety" step and "removal of the gallbladder" step were associated with the highest increase in the surgical time, suggesting the existence of technical issues with these tasks. The technical issues that affect surgical performance are described as follows.

\section{Endoscopic View-Related Issues}

Our analysis shows that the task of adjusting the endoscopic view is related to the lack of stability of the endoscope. In fact, during dissection, the endoscope does not remain stationary within the peritoneal cavity given the lack of supporting structure. The endoscope must be adjusted continually to maintain focus on the surgical site. Moreover, the lost of tension in the tissue when it is cut during the dissection task can move the endoscope violently in an unpredictable manner, requiring readjustment of the field and angle of view.

The finding of longer operative time due to continual endoscope adjustment is not surprising, yet it illustrates the inappropriateness of the tools used in NOTES. In fact, the flexible endoscopes were originally designed for intralumenal use (within the lumen of a tubular structure such as a colon) where the walls of the structure guide the endoscope and ensure the stability of the viewing platform. In NOTES, the flexible endoscopes are used translumenally within the large spacious peritoneal, cavity leading to the instability of the platform.

Some surgeons have tried to overcome this limitation by using rigid endoscopes (Roberts, et al., 2012). However, these visualization tools have different drawbacks that limit their use in the NOTES technique. For instance, they do not support the insertion of extra tools, thus requiring the use of additional abdominal ports (Auyang, Santos, Enter, Hungness, $\&$ Soper, 2011). Also, rigid endoscopes have limited viewing angles due to the lack of maneuverability (Noguera, Cuadrado, Dolz, Olea, \& García, 2012).

\section{Endoscopic Instruments-Related Issues}

Our analysis shows that the flexibility of the endoscope not only disturbs the visualization tasks, but also the control of the instruments. In fact, the lack of stiffness of endoscopic instruments leads to an even more limited haptic feedback to the surgeon compared to laparoscopic surgery. This limits the surgeon's perception of the contacts between the tools and tissue, and subsequently disturbs the execution of the dissection tasks.

Moreover, the size of the dissection instrument tip is smaller than the tips of instruments used in laparoscopic surgery. In fact, they are only 2-3 millimeters in diameter while the laparoscopic instruments are 5-10 millimeters in diameter. This reduces the size of contact surface between the instrument and the tissue, which in turn increases the time needed to dissect the same amount of tissue.

Finally, the instruments are inserted through the working channels of the flexible endoscopes and arrive in parallel into the peritoneal cavity. This leads to a limited triangulation of the instruments than in laparoscopic surgery and restricts the movements of the tools. This issue contributes also to increase the dissection time in NOTES. This is yet another illustration of the inappropriateness of the tools used in the NOTES technique which affects surgical performance.

New platforms have been developed to address some of these issues (Swanström, Swain, \& Denk, 2009; Yang, et al., 2010). They have yet to be evaluated, and validated for clinical use.

\section{CONCLUSION}

Even though the emerging NOTES technique is considered more desirable by patients, it is currently in the experimental stage and the technical problems outweigh the potential benefits. In fact, our study highlighted the existing technological issues related to this technique and their effects on surgical performance. The inappropriateness of tools currently used in NOTES for visualization and manipulation increases the time necessary to accomplish the surgical tasks such as dissection, and constrains the development of this technique into wide use. 
Our findings suggest that new instruments dedicated to the NOTES technique need to be designed to overcome these technical issues. In this context, our methodology can be a valuable tool for providing design recommendations and for the assessment of the newly designed instruments.

Collaboration between clinicians, human factors engineers, and the medical device industry is needed for the development of innovative and effective surgical tools.

\section{Design Implications}

Based on our analysis, it is clear that there is a mismatch between the functionality of the NOTES instruments and the surgical task objectives. Furthermore, the usability of the surgical tool is diminished by the physical constraints of the use environment. For instance, a rigid platform that can provide stability of endoscopic tools can overcome some of the endoscopic views/instruments issues. Rigid platforms can also be used to capture and magnify the haptic feedback allowing the surgeons to better perceive the contacts between tools and organs. Finally, because NOTES requires the surgeons to be adept in laparoscopic surgery as well as in advanced flexible endoscopy, dedicated training programs will be necessary to facilitate the learning of this technique. In this context, our methodology can be used to design training tools through modular sections corresponding to the hierarchical decomposition, and also to evaluate the surgeon's performance and learning curves in modular manageable units.

\section{REFERENCES}

Asakuma, M., Perretta, S., Allemann, P., Cahill, R., Con, S. A., Solano, C., . . . Marescaux, J. (2009). Challenges and lessons learned from NOTES cholecystectomy initial experience: a stepwise approach from the laboratory to clinical application. Journal of hepatobiliary-pancreatic surgery, 16(3), 249-254.

Auyang, E. D., Santos, B. F., Enter, D. H., Hungness, E. S., \& Soper, N. J. (2011). Natural orifice translumenal endoscopic surgery (NOTES): a technical review. 25(10), 3135-3148.

Berguer, R., Forkey, D. L., \& Smith, W. D. (1999). Ergonomic problems associated with laparoscopic surgery. Surgical Endoscopy, 13, 466-468.

Breedveld, P., \& Wentink, M. (2001). Eye-hand coordination in laparoscopy - An overview of experiments and supporting Aids. Minimally Invasive Therapy and Allied Technologies, 155-162.

Cao, C. G., \& Milgram, P. (2000). Case studies of disorientation in minimally invasive surgery. Proceedings of 44th Annual Meeting of the Human Factors and Ergonomics Society and XIVth Triennial Congress of the International Ergonomics Association, 4, pp. 169-172.

Cao, C. G., MacKenzie, C. L., Ibbotson, J. A., Turner, L. J., Blair, N. P., \& Nagy, A. G. (1999). Hierarchical decomposition of laparoscopic procedures. Studies in health technology and informatics, 62, 83-89.
Cuadrado-Garcia, A., Noguera, J. F., Olea-Martinez, J. M., Morales, R., Dolz, C., Lozano, L., . . Pujol, J. J. (2011). Hybrid natural orifice transluminal endoscopic cholecystectomy: prospective human series. Surgical Endoscopy, 25(1), 19-22.

Jones, D. B., Maithel, S. K., \& Schneider, B. E. (2006). Laparoscopic Cholecystectomy. In D. B. Jones, S. K. Maithel, \& B. E. Schneider, Atlas of Minimally Invasive Surgery (1st ed., pp. 12-39). Woodbury (CT): Cine-Med, Inc.

Kondo, W., Branco, A. W., Branco Filho, A. J., Noda, R. W., Tessmann Zomer, M., Charles, L., \& Bourdel, N. (2011). Transvaginal Natural Orifice Transluminal Endoscopic Surgery (Notes): Surgical Technique and Results. In A. Darwish (Ed.), Advanced Gynecologic Endoscopy.

MacKenzie, C. L., Cao, C. G., Ibbotson, J. A., \& Lomax, A. J. (2001). Hierarchical decomposition of laparoscopic surgery: A human factors approach to investigating the operating room environment. Journal of Minimally Invasive Therapy and Allied Technologies (MITAT), 10(3), 121-127.

Noguera, J. F., Cuadrado, A., Dolz, C., Olea, J. M., \& García, J. C. (2012). Prospective Randomized Clinical Trial Comparing Laparoscopic Cholecystectomy and Hybrid Natural Orifice Translumenal Endoscopic Surgery. Surgical Endoscopy, 26(12), 3435-3441.

Roberts, K. E., Shetty, S., Shariff, A. H., Silasi, D., Duffy, A. J., \& Bell, R. L. (2012). Transvaginal NOTES Hybrid Cholecystectomy. Surgical Innovation, 19(3), 230235.

Stassen, H. G., Dankelman, J., \& Grimbergen, K. A. (2001). Man-machineaspects of minimally invasive surgery. Annual Reviews in Control, 25, 111-122.

Swanström, L., Swain, P., \& Denk, P. (2009). Development and Validation of a New Generation of Flexible Endoscope for NOTES. Surgical Innovation, 16(2), 104-110.

Tessier, C., Zhang, L., \& Cao, C. (2012). Ergonomic considerations in natural orifice translumenal endoscopic surgery (NOTES): A case study. Work: $A$ Journal of Prevention, Assessment and Rehabilitation, 4683-4688.

Yang, K., Sun, Z., Kencana, A., Huynh, V., Rasouli, M., Phee, S., . . Ho, K. (2010). Enhancement of spatial orientation and haptic perception for master-slave robotic Natural Orifice Transluminal Endoscopic Surgery (NOTES). IEEE Conference on Robotics Automation and Mechatronics (RAM), (pp. 15-18).

Zornig, C., Mofid, H., Emmermann, A., Alm, M., von Waldenfels, H. A., \& Felixmüller, C. (2008). Scarless cholecystectomy with combined transvaginal and transumbilical approach in a series of 20 patients. Surgical Endoscopy, 22(6), 1427-1429.

Zorron, R., Maggioni, L. C., Pombo, L., Oliveira, A. L., Carvalho, G. L., \& Filgueiras, M. (2008). NOTES transvaginal cholecystectomy: preliminary clinical application. Surgical Endoscopy, 22(2), 542-547. 